\title{
Integrating Students' Learning Styles and Learner Outcome to Develop the Teaching Strategy: A Case Study of the Event Planning Course
}

\author{
Xuehui Zeng ${ }^{*}$ \\ Event Management Department \\ Shanghai Polytechnic University \\ P.R china \\ xhzeng@sspu.edu.cn
}

\author{
Yan Wang \\ College of International Vocational Education \\ Shanghai Polytechnic University \\ P.R china \\ ywang612@hotmail.com
}

\begin{abstract}
The major purpose of education is to change the program participants. Therefore, learners are the reason for the learning activity in the first place. The objective of this paper is to discuss how to develop the teaching strategy by way of integrating students' learning style and learner outcome. The paper starts from the survey of the students' learning styles. It shows that among them, $51 \%$ are visual learners, $35 \%$ are auditory learners and $10 \%$ kinesthetic learners. There are very few who are mixed learners. Learner outcome is developed afterwards concerning cognitive, affective, and psychomotor domains. These are the three domains of learning. Research shows that the effective teaching strategy is to begin with an expository approach move on to participatory learning, and end the process with evaluative learning, thus providing students with as many experiences as possible. It is hoped that the findings of the paper will help the facilitators to create and format the successful learning experience for the students in order to achieve the goal of learner outcome. Limitations for further research are also discussed in the paper.
\end{abstract}

Keywords—Learning styles, Learner outcome, teaching strategy

\section{INTRODUCTION}

The world is keep changing and the future students of event management will enter the changing environment upon graduation.[3-5]The emphasis in higher education has also changed from educator-centered learning to active student involvement and participation in the educational process. The goal is to prepare the students with superior communication, critical-thinking and problem-solving skills for the future labor market. When teaching staff want to improve student learning, it is very important that they know and understand how students learn. Moreover, individual students have their own learning styles, (Paraskevas \& Sigala, 2003). [8] Therefore, survey on the students' learning style, study on domains of learning are the two important elements for the educators to develop the teaching program. This is also the foundation for defining the learner outcome for the overall teaching activities.

\section{Methodology}

\section{A. Research background}

How to develop the teaching component of a lecture, ensuring successful learning and increase the effective and value of teaching activity is a big challenge for the facilitators. Teachers need skills to be better prepared to meet this challenge. Knowles' theory of andragogy is an attempt to develop a theory especially for learning success. In his theory, Knowles suggests that the design of learning should include experiential learning and problem solving. [8] In practical terms, this means that instruction for the students' needs to focus not only on the content but also on the process. Techniques like case study, role-play, simulations, and selfevaluation might be very useful to meet this requirement. [2]

The context for this paper is an event management course taught to third year students at Shanghai Polytechnic University, China. Case was used as a method to investigate the students' learning styles and needs for the teaching design in order to achieve the teaching objectives.

Behaviors and attitudes can vary greatly from one generation to the next, understanding the predisposition of the student will help the educators to better understand the audience and enable them to adapt content and format appropriately. Our students are born around 1995, in an era called The Millennial (born 1982-present). Barbara C. Nichols argues in her book Professional Meeting Management, fifth edition, that they are the most nurtured and most adultsupervised of the generations. They think big, prefer team play and want a team-oriented experience in learning. [8]

\section{B. Survey and findings of the students' learning styles}

Learning styles are ways that shows how people learn and store information. The style of the teaching should be based on the characteristics and the needs of the students and tailored to their learning styles. Facilitator s need to recognize that each student prefers a particular style of learning and that using one method of presenting material will not necessarily be beneficial to everyone. The three basic learning styles are visual, auditory, and kinesthetic. [2], [6-7] 
According to the research, approximately $40 \%$ of the populations are visual learners, who like to see things written down. They learn best through software slides such as Power point, diagrams, and illustrations. Auditory learners make up approximately $30 \%$ of the population. They learn by hearing and listening, understand and remember things they have heard, store information by the way it sounds and have an easier time understanding spoken instructions than written ones and they often learn by reading out loud because they have to hear it or speak it in order to know it. Kinesthetic learners make up the final $30 \%$ of the population. These learners need time to practice. They enjoy hands-on activities and learn best by imitation and practice. Through a careful needs analysis, facilitators can learn more about students' learning style preferences, and their content needs. Synthesizing this information carefully will help facilitators design a program that will match the needs of the individuals in the group. Generational predispositions, as well as the innate learning styles of the participants affect learning outcomes and should be considered for success.

As to this paper, we select the student learning style survey form from the internet, http://www.educationplanner.org,[9] a public service of the Pennsylvania Higher Education Assistance agency (PHEAA). There are 24 questions with 24 different situations. 90 students conduct the on-line survey and 86 students report the score of the results. Findings shows that among the 86 reports, 30 are auditory learners (A) which is $35 \%, 44$ are visual learners (B), which is $51 \%, 9$ are kinesthetic learner(C), which is $10 \%$. Besides, there are three who have the preference of mixed learning style $(B+C, A+C$ or $A+B+C)$, as shown in table 1.

TABLE I. LEARNING STYLE SURVEY RESULTS

\begin{tabular}{lcc}
\hline Learning styles & Number of students & Percentage ( \% ) N=86 \\
\hline Auditory learner (A) & 30 & $35 \%$ \\
\hline Visual learner (B) & 44 & $51 \%$ \\
\hline Kinesthetic learner (C) & 9 & $10 \%$ \\
\hline B+C & 1 & $1 \%$ \\
\hline A+C & 1 & $1 \%$ \\
\hline A+B+C & 1 & $1 \%$ \\
\hline
\end{tabular}

\section{Domains of learning and learner outcome}

Learning is change. It modifies behavior or performance. Awareness of the domains of learning is the foundation of planning teaching programs. According to the research, there are three areas of behavior, which are generally referred to as the domains of learning. They are cognitive, affective, and psychomotor. [8]

The cognitive domain (knowledge) is the knowledgeacquisition phase of learning and emphasizes intellectual outcomes, such as comprehension and analysis skills. It attends to what the learner knows or understands and encompasses recall or recognition of information and the development of intellectual skills that provide the learner with the ability to conduct rational tasks.
The affective(attitude)domain emphasis on feelings and emotions, concerning with how the learner feels and the changes in terms of interest, attitudes, feelings, and values, as well as how they internalize values and beliefs. The psychomotor (skills) domain focuses on how a learner uses manual skills, with an emphasis on the performance.

The psychomotor domain is the "doing” phase of learned behaviors. It is an integral part of performance because the cognitive and affective domains are interrelated with performance and are considered as the prerequisites. The learner must have the knowledge and the desire in order to actually perform the required or specified task, and be able to integrate previously acquired knowledge and attitudes in order to accomplish more complex tasks. Domains of learning are positively related when defining the learner outcome. As shown in Table 2.

TABLE II. DOMAIN OF LEARNING AND KEY POINTS OF LEARNER OUTCOME

\begin{tabular}{ll}
\hline Domains of learning & Key points of learner outcome \\
\hline Cognitive domain (knowledge) & Knowledge-acquisition phase of learning \\
\hline Affective domain (attitude) & Change on emotion, attitude, interest, feelings, values etc. \\
\hline Psychomotor domain & $\begin{array}{l}\text { "doing” phase of learning behaviors, integrate knowledge and attitude for more } \\
\text { complex tasks }\end{array}$
\end{tabular}

\section{DISCUSSIONS}

Learning experience and the teaching strategies should be well matched to ensure the learner outcome. [1] It needs to be formatted and developed in a professional way. The methods of instruction that are most adaptable to the learning environment are expository, participatory, and evaluative. In practice, these should be organized through proven methods known as organizational pattern in the teaching process. 
In expository learning, the instructor presents to the learners and the learners remain passive and watch or listen. This is generally the format for large group learning, which is very efficient for conveying information or content. The environment is formal, structured. The challenge for the facilitators is to use a variety of techniques and strategies to maintain learner interest and involvement. As in event management course Part II, Planning and Implementing Fairs and Exhibition (Organizer's Side), defining the exhibition subject is knowledge-based material. As most of the students are visual learners, teachers can use PowerPoint to explain how to create subject for a new exhibition and use mind map to help student sum up the possible ways and any options to find the subject.

When moving to discuss the elements for defining the subject, participatory learning needs to be organized, because the participants can share knowledge and experience and work together to learn. [6]The role of the instructor is to encourage the students actively involved in the process. With the knowledge learnt in the first step, a case study is delivered to a group for further discussion on the factors influencing the subject defining. Finally, the speaker of the group presents the result of their consideration. They all agree that market prospect, market scale, market channel and ROI are the four important factors to consider. The greatest challenge in small group activities is that the group leader must be an attentive listener because learner participation is the primary focus.

The final step is the evaluation learning method, which tests whether participants learned what was expected, and if they can use the information effectively. Verbal questions, tests and exercises, and self-assessment are used to test a participant's knowledge of the subject matter. Upon completion of case study, students are asked to draft a framework for the prospectus based on the fair concept. This task is more complex and helps to check the student performance.

\section{CONCLUSIONS}

Once the goals of the instruction have been established, learning styles of the students should be investigated and be used as inputs to develop the teaching program which support these goals. Then learner outcome should be followed consequently. In other word, learner outcomes are directions, instructions and assist the facilitator in selection content, resource material, and appropriate instructional methods. The major purpose of the activity is to change the program participants. Learners are the reason for the activity in the first place. Finally, the best educational programs combine all three methods of instruction. One effective program design is to begin with an expository approach, move on to participatory learning, and end the process with evaluative learning, thus providing students with as many experiences as possible.

\section{LIMITATIONS FOR FURTHER RESEARCH}

The study population was limited to two classes of the third year students majoring in event management in one university, that is, Shanghai Polytechnic University. Therefore the findings of the study maybe limited and the sample may not represent the result of other universities. Besides, the study is based only on quantitative findings from questionnaires. Further research should be considered to include qualitative findings from interview. Questions like workload with different learning experience, assessment, perception of good teaching and good teachers, relationship with teaching staff, change in learning approaches, suggestions to teaching and the curriculum design, etc. By undertaking both quantitative and qualitative research, we can get the overall picture of how to integrate learning style and learning outcome to develop the fruitful teaching strategies.

\section{ACKNOWLEDGEMENT}

This research was supported by the Tourism Management Discipline Research Program funded by Shanghai Polytechnic University, P.R. China (Grant NO. XXKPY1607).

\section{REFERENCES}

[1] Scott A. Lee, Increasing Student Learning: A Comparison of Students' Perceptions of Learning in the Classroom Environment and their Industry-Based Experiential Learning Assignments, Journal of Teaching in Travel \&Tourism, vol.7(4), pp. 37-53, 2007.

[2] Noel Scott, An Evaluation of the Effects of Using Case Method on Student Learning Outcomes in a Tourism Strategic Planning Course, Journal of Teaching in Travel \& Tourism, vol.7(2), pp. 21-40, 2007

[3] Pauline Sheldon, Dan Fsesnmaier, Karl Woeber, Chris Cooper, and Magda Antonioli, Tourism Education Futures, 2010-2030: Building the Capacity to Lead, Journal of Teaching in Travel \& Tourism, vol.7 (3), pp. 61-68, 2007.

[4] Lee-Jaye Slaughter, and Lisa Ruhanen, Using Action Learning to Improve Assessment: A Case Study from an Undergraduate Tourism Management Course, Journal of Teaching in Travel \& Tourism, vol.7 (2), pp. 1-19, 2007.

[5] Michael M. G. Scantlebury, Rules for the Road (RFTR): Establishing a Positive Atmosphere for Learning, Journal of Teaching in Travel \& Tourism, vol. 8(4), pp. 395-400, 2008.

[6] Ahmed Hassanien, Student Experience of Group Work and Group Assessment in Higher Education, Journal of Teaching in Travel \& Tourism , vol. 6(1), pp. 17-39, 2006.

[7] Benny Chan, and Winnie Tang, Evaluating the Impact of University Teaching on Approaches to Learning of First- Year Hospitality Students, Journal of Teaching in Travel \& Tourism, vol. 6(1), pp. 41-59, 2006.

[8] Barbara C. Nichols, Professional Meeting Management, Professional Convention and Management Association, Fifth Edition, pp. 265-304, 2008.

[9] http://www.educationplanner.org 